\title{
材料试验检测技术在公路工程中的应用
}

\author{
陈旅鹏* \\ 商洛正大公路工程监理有限责任公司，陕西 726000
}

\begin{abstract}
摘 要: 对于我国城市建设的发展中, 公路的建设对于城市建设中至关重要, 因为公路的质量与我国人民的人身 安全以及公共交通秩序有着紧密的关联, 所以对公路建设材料的试验检测技术的合理应用直接关系最终公路的建设质 量, 并且可以最大程度地保证公路建设的安全性。本文对于主要针对公路工程中对于材料应用试验检测技术的应用进 行探索研究。
\end{abstract}

关键词：公路工程; 应用; 材料试验检测技术

\section{Application of Material Testing Technology in Highway Engineering}

\author{
Lv-Peng Chen* \\ Shangluo Zhengda Highway Engineering Supervision Co., Ltd., Shangluo 726000, Shaanxi, China
}

\begin{abstract}
For the development of China's urban construction, highway construction is very important for urban construction. Because the quality of highway is closely related to people's personal safety and public traffic order, the reasonable application of test and detection technology of highway construction materials is directly related to the final highway construction quality, and can ensure the safety of highway construction to the greatest extent. This paper mainly explores the application of material application test and detection technology in highway engineering.
\end{abstract}

Keywords: Highway engineering; Application; Materials testing technology

\section{一、前言}

对于我国城市的发展建设离不开公路的修建, 并且道路交通的进步可以有效地推动我国城市发展的进程, 因此公 路的建设就显得尤为重要 ${ }^{[1]}$, 因此, 要想保证公路建设质量, 就务必要保证施工材料的试验检测技术可以得到充分地 应用。

\section{二、材料实验建设技术对于公路工程的重要意义}

目前我国经济的飞速发展, 有效地带动了我国城市的建筑, 因此, 科技也在不断地进步, 促使了各种新型材料出 现, 也为我国的公路建设在施工材料方面提供了更多的新选择, 从而可以针对不同的工程建设而选择最佳适合的施工 材料, 并且对于公路的建设提供了更高的耐久性以及稳定性。但是要对新型的材料的质地进行判断, 可以通过材料试 验检测的技术对其进行分析, 这一检验环节对于公路的建设极为重要, 可以直接影响公路施工建设的最终效果, 可以 对工程施工的质量进行严格把控 ${ }^{[2]}$ 。

另外, 对于通过应用材料试验检测的技术对施工材料进行检验时, 最为重要的一点就是可以对公路工程造价进行 有效控制。在公路建设的过程当中, 控制施工成本造价极为重要, 可以通过合理应用材料试验检测的技术, 不仅可以 最大程度的保证材料的质量的同时, 可以选择最为适合, 且价格合理的施工材料进行建设, 使其发挥最大的效果, 并 且有效地控制施工造价 ${ }^{[3]}$ 。

通过合理应用施工试验检测技术可以有效地提升施工建设的速度进程。当通过试验检测技术选择最终使用的材料 之后, 可以最大程度地避免在施工过程中由于施工材料大大小小的问题导致工程建设中断的情况发生, 不仅可以保证

*通讯作者: 陈旅鹏, 1981年6月, 男, 汉族, 陕西丹凤人, 就职于商洛正大公路工程监理有限责任公司, 高级工 程师, 本科。研究方向: 公路工程试验检测。 
公路工程可以顺利地进行, 并且通过选择质量较好以及更为适合的材料有效减少施工工期, 降低的时间成本的投人, 最大程度地保证公路工程建设的施工效果。在新兴技术以及新型材料进人我国市场中后, 务必对其进行科学合理的试 验检测技术, 要保证材料的质量达到要求以及材料的规格符合施工建设的规定后将其进行合理的应用, 通过试验检测 的结果可以有效地为施工建设提供了较为有力的保证依据，从而促进在未来对其进行广泛地应用。

另外，在公路工程建设各个施工项目完成之后，需要对各个环节进行相应的检验工作，并且对施工质量做出相应 的评估方案, 施工材料的试验检测的结果可以作为公路工程施工检验的有力依据, 在一定程度上关系这最终的检验成 果，以及施工材料的试验检测的结果也可以为公路后期的维护工作提供有力根据 ${ }^{[4]}$ 。

\section{三、试验检测工程材料具体内容}

在公路建设过程当中, 施工企业需要对于施工现场需要使用的施工材料进行随机式的抽样检查, 检测的范围包 括集料、钢筋、砂石、水泥、沥青等等 ${ }^{[5]}$, 并且对于施工材料的原厂家以及施工材料的类型、品牌等进行分别式的检 测, 将施工原材料的表示, 原材料的质量以及寄存等质量信息进行严格的比对工作, 并对其进行充分的了解, 以及通 过工程建设实验室对于施工原材料进行检测, 使其检测的结果, 频率以及目标等等的数据进行记录, 并且针对检测的 数据是否符合公路施工建设的标准规范要求, 对检测作业进行相应的核对以及执行工作, 使自检工作最大程度地保证 其稳定性以及可靠性，如表1所示。

表1 工程材料检验

\begin{tabular}{|c|c|c|c|c|c|}
\hline 序号 & 样品名称 & 数量 & 样品要求 & 试验周期 (天） & 样品处置 \\
\hline 1 & 硂试块 & 3块 & $\begin{array}{l}150 \times 150 \times 150 \mathrm{~mm} \\
100 \times 100 \times 100 \mathrm{~mm}\end{array}$ & 2 & 样品破坏 \\
\hline 2 & 砂浆试块 & 6块 & $70.7 \times 70.7 \times 70.7 \mathrm{~mm}$ & 2 & 样品破坏 \\
\hline 3 & 砂子 & $10 \mathrm{~kg}$ & & 4 & 样品破坏 \\
\hline 4 & 石子 & $80 \mathrm{~kg}$ & 按设计要求 & 4 & 样品破坏 \\
\hline 5 & 水泥 & $12 \mathrm{~kg}$ & 按设计要求 & 35 & 样品破坏 \\
\hline 6 & 硅试配 & & 水泥 $30 \mathrm{~kg}$; 砂 $100 \mathrm{~kg}$; 石 $150 \mathrm{~kg}$ & 36 & 样品破坏 \\
\hline 7 & 砂浆试配 & & 水泥 $10 \mathrm{~kg}$; 砂 $40 \mathrm{~kg}$; 石 $10 \mathrm{~kg}$ & 36 & 样品破坏 \\
\hline 8 & 外加剂 & $4 \mathrm{~kg}$ & & 40 & 样品破坏 \\
\hline 9 & 抗渗试块 & 6块 & & 8 & 样品破坏 \\
\hline 10 & 蒸压砌块 & 9块 & $100 \times 100 \times 100$ & 4 & 样品破坏 \\
\hline 11 & 空心砌块 & 5块 & & 4 & 样品破坏 \\
\hline 12 & 红砖 & 25块 & & 15 & 退回15块 \\
\hline 13 & 多孔砖 & 25块 & & 15 & 退回15块 \\
\hline 14 & 空心砖 & 25块 & & 15 & 退回15块 \\
\hline 15 & 钢筋原材 & 4 根 & $40 \mathrm{~cm} 2$ 根, $30 \mathrm{~cm} 2$ 根 & 3 & 样品破坏 \\
\hline 16 & 盘圆 & 3 根 & $40 \mathrm{~cm}$ & 3 & 样品破坏 \\
\hline
\end{tabular}

(一) 水泥的试验检测

在对水泥进行试验检测过程中, 需要检测水泥的凝结时间, 水泥的稠度以及用水量, 检测水泥的细度, 胶砂强度 等 ${ }^{[6]}$ 。并且对于同一厂家, 相同的批次货号以及同一生产日期, 同一规范的水泥进行袋装, 散装的方式进行分批次检 测，并且对其检测的频率控制的每一季度进行一次检测。

\section{(二) 骨料的试验检测}

在实验检测骨料时，要根据骨料截面的大小程度，使用不同的检测方式，将细骨料与粗骨料进行分别的检测 工作 ${ }^{[7]}$ 。要检测细骨料的含泥量, 含水量以及密度; 检测粗骨料时就需要检测其磨光值, 磨耗值, 吸水率以及篮分 等。并且在对骨料进行检测过程中需要严格按照《公路工程集料试验规程》中的要求, 并且需要在使用骨料之前对 粗骨料以及细骨料进行相应的样品检测, 当骨料作为基层与底基层是, 要在每 $2000 \mathrm{~m}^{3}$ 检测两个样品, 当应用在面层 时, 要对每个批次中抽取两个样品进行检测。

(三) 砂石的试验检测 
在对砂石进行检测时, 需要对其篮分, 密度, 容重以及含泥量等进行检测。如图1所示, 在检测过程当中, 要对 于同一料源以及挖掘单位可以根据每 $400 \mathrm{~m}^{3}$ 的方式进行检测, 并且对于不同批次的砂料必须通过抽样的形式对其进行 一次检测。

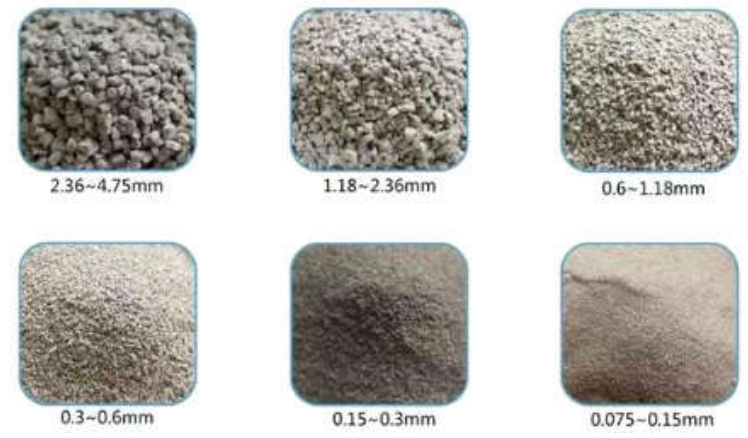

（四）钢筋的试验检测

图1 砂石的试验检测

要检测钢筋的屈服强度、弯曲能力、抗拉强度、断后伸长率等，另外对于同一钢筋生产厂家中同一质量、同一等 级、同一炉号的钢筋要进行以60吨为一批次，对其随机抽样2根进行冷弯试验以及拉伸试验，如图2所示。

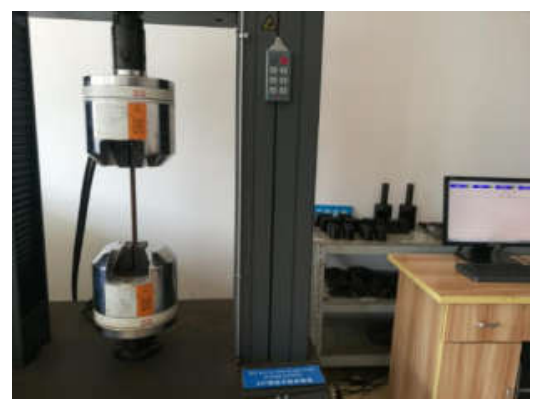

图2 钢筋试验检测

（五）沥青的试验检测

在对沥青进行检测时, 需要检测其软化指标、老化指标、针人度以及延伸度等, 并且要在公路工程在进行铺油之前 与施工建设之间进行沥青原材料的检测作业。在实际检测过程中，可以根据500吨的进货方式，对其进行批次的试验检 测工作。可以通过没 1000 吨对其进行一次检测，要检测三次沥青中的蜡含量，并对没车都进行四大目标的检测 ${ }^{[8]}$ 。

在对沥青材料进行检测时可以参照《公路工程沥青及沥青混合料实验规程》以及 《公路沥青路面施工规范》。对 于沥青材料的检测工作要完善其记录以及存档工作, 并且要根据材料不同种类进行不同的检测工作。与此同时, 沙土 对于公路维修时使用率较多的材料也应对其进行试验检测作业, 包括检测其密度、颗粒的分析、含水率、击实试验以 及界限含水率等。

\section{四、试验检测公路工程施工才俩了质量的相应方法}

\section{(一) 检测材料}

在对施工材料进行检测作业过程中，务必要严格按照国家相关公路建设材料的规范度以及工程建设计划方案来进 行工作, 要对公路建设时所需要的原材料包括石、沙、土、水泥、沥青、石灰、钢筋等等进行严格的核对工作, 并且 要保证选择使用的原材料最为适合应用到该公路建设中, 保证材料的科学性以及合理性。例如, 在选择土时, 要避免 选择有机土以及黏性黏土; 选择砂料时, 要重视砂砾的含泥量, 颗粒级配以及水泥砂石的配比等问题, 从而最大程度 的保证材料的坚固性，增加实用性的同时有效地对施工质量进行控制 ${ }^{[9]}$ 。

（二）实验规范性

在进行试验过程中, 要格外注意混合料的配比的含水量, 从而保证其试验检测方式的正确性, 以及配比的精确 性; 对于水泥混凝土的材料配比要主要考虑其组成的原材料, 然后通过施工建设的要求以及施工周边的环境因素等问 题进行拌合; 对于沥青的混合料的密度、饱和度、稳定性、流值以及孔隙率等进行检测, 保证其数据指标符合沥青质 
量方面的需求，也可使用 “沥青混合料马歇尔稳定度及浸水马歇尔实验”的方法。

(三) 跟踪测试

不仅要在公路建设施工之前进行施工材料的试验检测工作, 还应在公路施工的全部过程中, 根据不同的施工建设 的流程以及施工需求来进行针对性地材料试验检测的工作, 将试验检测技术贯彻施工建设的全部过程当中。在共建施 工建设过程中全程控制施工的质量可以有效地提升公路工程的建设效率，保证施工建设在规定的工期内完成。对于自 检工作可以及时发现施工过程中出现的事物以及质量问题, 从而可以对其进行修复改正, 因此不单单保证施工整体质 量的同时提升了工作效率，并且最大程度地降低了施工成本的投人。

(四) 检验监测工作

当公路施工建设个每一个施工环节完工之后都应对其进行检验核对, 检测其工程参数以及工程的质量方面, 一旦 在检验中存在不合格的现象时, 务必将其返工。在检验过程中, 可以根据施工之前试验检测材料的质量数据以及在施 工过程中对材料质量的跟踪数据作为参照, 通过其数据开展合理科学的检测方法, 对公路工程的整体进行评估, 最终 通过评估的结果来决定公路工程需要返工还是竣工。

\section{五、其他检测技术的使用}

(一) 机械检测技术

因为有较多种类的机械检测仪器, 例如指针、弹簧等等, 这种检测设备都可以有效的保证公路工程建设的安全 性。另外, 这些检测设备还可以将构建的变化传送到专门的设备仪器当中, 从而可以更加准确地对公路进行检测工 作。通过机械的检测技术主要可以将构建变化转变为长度变化, 这样就可以检测其构件的变化, 从而可以进一步地检 测公路中产生的所有变化，使公路建设的安全性得以提升。

(二) 检测内部缺陷工作

对于在公路建设过程中, 都会存在阿达学习的问题, 例如在混凝土的构架中就会出现分层, 碎裂等情况, 从而降 低混凝土的牢固性, 因此要针对这一情况对公路内部的问题进行相应的检测, 一旦检测出问题所在, 务必进行及时地 解决处理。但是由于一些问题不能够直观发现, 因此需要通过采取相应的雷达监测技术或者声波检测技术, 这些技术 都可以满足对公路内部检测的需求, 从而可以有效的检测公路内部存在问题。然后根据检测的最终结果对公进行整体 评判, 并对检测结果进行验证工作，最后对其验证结果来合理地安排下一步的修复工作内容。

\section{六、结束语}

综上所言, 公路的建设对于城市的发展有着极为重要的作用, 在实际的公路施工建设当中, 不仅仅要保证公路的安 全性, 更要保证公路的施工质量, 因此要合理采用先进的材料试验检测技术, 保证施工材料的适用度以及质量的同时, 提升施工的整体质量, 并且在建设过程中, 可以及时发现问题, 并对其进行修复工作, 从而减少施工成本的投入的同时 缩短建设工期。因此要保证检测工作的准确性，就需对其进行相应的完善，来保证我国公路建设行业的稳定发展。

\section{参考文献:}

[1]任小奋.公路工程的土体和路面基层材料试验检测研究 [J].山西建筑, 2019,45(02):140-142.

[2]吴肖肖.试论公路工程路基用土和路面基层材料试验检测 [J].低碳世界, 2019,9(03):226-227.

[3]张兴钦.试论公路工程路基用土和路面基层材料试验检测 [J].建材与装饰, 2019(33):247-248.

[4]王权势.公路工程中材料试验检测技术的运用 [J].中国公路, 2020(07):112+114.

[5]王悦玫.材料试验检测技术在公路工程中的应用探究[J].运输经理世界, 2020(03):55-57.

[6]史茜.公路工程材料试验检测管理现状分析[J].运输经理世界, 2020(03):119-121.

[7]赵凌.公路工程材料试验检测技术[J].产业科技创新, 2019,1(18):41-42.

[8]韩娟.材料试验检测技术在公路工程中的运用分析 [J]. 甘肃科技纵横, 2020,49(11):67-69+72.

[9]黄禽金.材料试验检测技术在公路工程中的应用 [J].低碳世界, 2020,10(12):191-192. 